\title{
MEROSTACHYS SKVORTZOVII SENDULSKY: ASPECTOS BOTÂNICOS E ECOLÓGICOS - UMA REVISÃO
}

\section{MEROSTACHYS SKVORTZOVII SENDULSKY: BOTANICAL AND ECOLOGICAL ASPECTS - A REVIEW}

\author{
SCHWARZBACH, Luciana L. C. ${ }^{*}$; NEGRELLE, Raquel R. B. ${ }^{2 ;}$ SANQUETTA, Carlos R. ${ }^{3}$ \\ 1- Bióloga (UFPR) Parte da dissertação de Mestrado em Agronomia - Produção Vegetal - UFPR \\ 2- Doutora em Ecologia e Recursos Naturais, Professora Adjunta do Departamento de Botânica da \\ Universidade Federal do Paraná, Orientadora. \\ 3- Engenheiro Florestal; Professor do Departamento de Ciências Florestais; UFPR; Bolsista CNPq, \\ Co-orientador. \\ * e-mail: luciana.correa@ @ gmail.com
}

\section{INTRODUÇÃO}

Os bambus são plantas que ocorrem naturalmente em todos os continentes, exceto no Europeu, apresentando mais de 1.200 espécies espalhadas pelo mundo, divididas em cerca de 90 gêneros. São um grupo diverso com capacidade de propagar-se em regiões inóspitas, resistir a extremos de temperaturas e sobreviver em solos de baixa fertilidade. Crescem como pequenas gramíneas ou chegam a extremos de 40 metros de altura (LOPEZ, 1974). Além disso, o diâmetro também varia em larga escala e dentre as espécies existem as consideradas anãs, com pequeno diâmetro e porte (inferior a $1 \mathrm{~m}$ ) e outras gigantes com diâmetro superior a $20 \mathrm{~cm}$ (STAPLETON, 1987). No entanto, segundo Lopez (1974), as características botânicas do bambu ainda não são totalmente conhecidas, uma vez que estas plantas podem florescer em intervalos de 30, 60, 90 e até 100 anos, variando de acordo com a espécie, e as flores e frutos são indispensáveis para este conhecimento.

Dentre as inúmeras possibilidades de uso do bambu pode-se citar: a fabricação de papel, carvão, móveis, cestarias, luminárias, cortinas, objetos de decoração, utensílios domésticos, na construção civil e rural, irrigação e conservação do solo e como elementos de projetos paisagísticos (PANT; VARMALI, 1981; CROUZET; CROUZET; STAROSTA, 1998). O bambu pode ser utilizado, ainda, como combustível, substituindo o uso tradicional e, muitas vezes, predatório de madeiras importantes para os ecossistemas. Por ser um recurso natural renovável, a intensificação de seu uso pode contribuir para diminuir a pressão da procura por madeiras nobres - especialmente aquelas em risco de extinção - bem como também complementar o uso de madeiras de florestas plantadas, cuja demanda cresce além da capacidade instalada no país (IBAMA, 2008). Desta forma, a exploração sustentável de espécies nativas de bambu, subsidiada por estudos ecológicos é um nicho importante a ser explorado como fonte de renda, especialmente no Brasil onde os bambus nativos ainda não são utilizados em toda sua potencialidade.

Visando contribuir para o melhor entendimento da flora brasileira no que concerne à família Poaceae, Subfamília Bambusoideae, apresenta-se resultado de revisão bibliográfica sobre aspectos botânicos e ecológicos de Merostachys skvortzovii Sendulsky, espécie de ocorrência freqüente no bioma Floresta Ombrófila Mista no Estado do Paraná. 


\title{
2. DESENVOLVIMENTO DO TEMA
}

\subsection{CLASSIFICAÇÃO BOTÂNICA}

Segundo o sistema APGII, em termos taxonômicos, Merostachys skvortzovii Sendulsky ${ }^{1}$ está categorizada em (SOUZA; LORENZI, 2005):

\author{
Família Poaceae (Gramineae) \\ Subfamília Bambusoideae \\ Tribo Bambuseae \\ Subtribo Arthrostylidiinae: \\ Gênero Merostachys Sprengel. \\ Espécie Merostachys skvortzovii Sendulsky.
}

A família Poaceae é considerada uma das maiores do grupo das Angiospermas, apresentando ampla distribuição geográfica com cerca de 9000 espécies distribuídas em 650 gêneros. No Brasil ocorrem 1500 espécies pertencentes a 180 gêneros. São plantas de grande importância econômica, com destaque o cultivo para fins alimentícios, mas também com usos artesanal, ornamental e medicinal. As gramíneas podem compor campos, como forrageiras e, raramente, podem aparecer no interior de formações florestais, exceto pelas Bambusoideae (SOUZA; LORENZI, 2005).

Pertencente à subfamília Bambusoideae, o gênero Merostachys foi descrito por Sprengel e seu nome tem origem do grego meris/meros que significa porção/ parte e stachys que significa espiga (QUATTROCCHI, 2006).

A subtribo Arthrostylidiinae, à qual pertence o gênero Merostachys, é formada por um grupo monofilético de bambus lenhosos neotropicais e é composta de 13 gêneros e cerca de 165 espécies descritas, cujas características morfológicas muitas vezes se sobrepõem tornando a taxonomia do grupo difícil (TYRRELL et al., 2007).

A espécie Merostachys skvortzovii Sendulsky foi descrita em 1995, por Tatiana Sendulsky, sendo o epíteto skvortzovii em homenagem ao botânico Boris Skvortzov, que dedicou os últimos anos de sua vida ao estudo da flora brasileira (SENDULSKY, 1995; QUATTROCCHI, 2006).

De acordo com Sendulsky (1995), há um grupo de 10 espécies de Merostachys de difícil distinção entre si, que não podem ser agrupadas sob o mesmo nome e que muitas vezes são erroneamente identificadas como Merostachys multiramea Hackel, entre as quais está inserida M. skvortzovii. Algumas delas já foram descritas e apresentam equívoco de identificação e outras são claramente novas espécies, como é caso de M. skvortzovii.

\subsection{DESCRIÇÃO BOTÂNICA}

O gênero Merostachys, de maneira geral, é representado por plantas lenhosas, de colmos eretos com uma leve curvatura no ápice e inflorescências racemiformes, apresentando uma relação taxonômica próxima ao gênero Rhipidocladum (LONDOÑO, 1996). Inclui espécies semelparas e monocárpicas, ou seja, que apresentam apenas um evento de reprodução sexuada em sua vida, morrendo sincronicamente após o mesmo.

\footnotetext{
${ }^{1}$ Identificação botânica realizada por Dr. Tarciso Filgueiras, IBGE - Brasília (DF).
} 
Merostachys skvortzovii é um bambu lenhoso que apresenta um crescimento vegetativo por meio de rizomas do tipo paquimorfo, o qual se caracteriza por ser sólido, grosso, curto, achatado dorsiventralmente e curvado para cima. Apresenta colmos (4-6 m) que formam densas touceiras, nós salientes com um toque de uma pubescência esbranquiçada acima e abaixo; inflorescências $(1,5-3 \mathrm{~cm})$ terminais nas folhas dos ramos, espiguetas solitárias, com uma flor, acuminadas e fusiformes e 2 glumas desiguais; cariopses com $5 \mathrm{~mm}$ de comprimento, ovais, arredondadas no ápice, rostradas, amarelo acinzentadas, macias com hilo linear e embrião dificilmente visível (Figura 5: a, b e c) (SENDULSKY, 1995; CLAYTON; HARMAN; WILLIAMSON, 2002).

a)
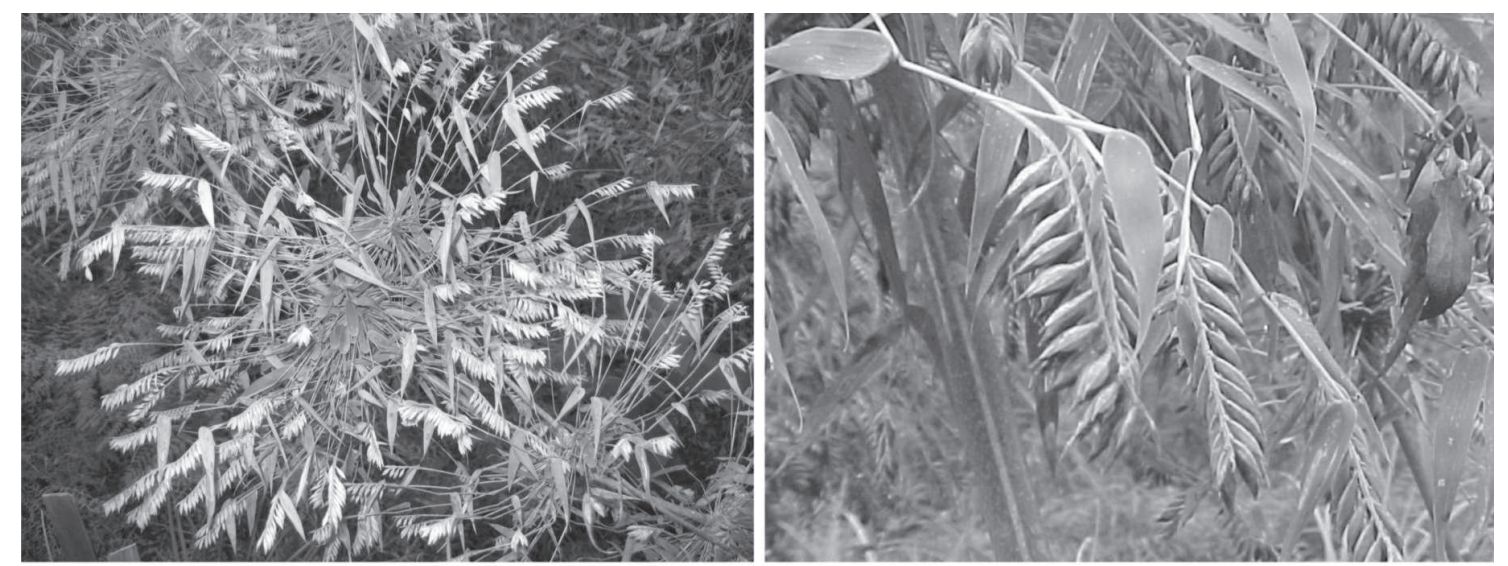

b)

c)

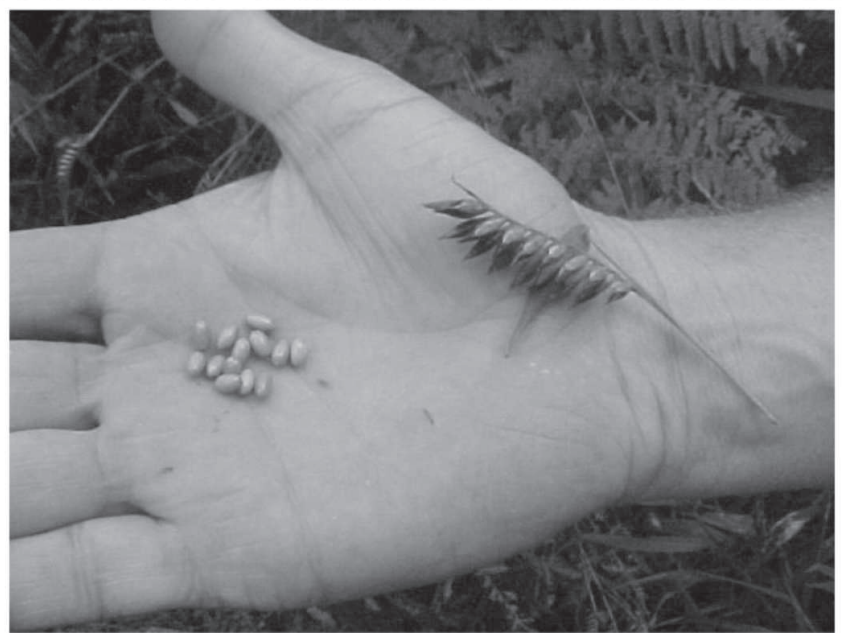

FIGURA 5 - a) Visão geral de um ramo com inflorescências de $M$. skvortzovii; b) Inflorescências de M. skvortzovii; c) Cariopses de M. skvortzovii.

FONTE: SANQUETTA (2002) 


\subsection{DISTRIBUIÇÃO E OCORRÊNCIA}

O gênero Merostachys apresenta cerca de 48 espécies distribuídas desde a Guatemala até a Argentina, sendo a maior diversidade encontrada no Brasil. Encontram-se desde o nível do mar até $1500 \mathrm{~m}$ de altitude. Das espécies brasileiras, 87\% encontram-se distribuídas nas florestas montanas do leste e sudeste brasileiro e desempenham um papel ecológico importante nos ecossistemas em que se encontram, devido à sua influência sob a regeneração de espécies arbóreas (SENDULSKY, 1995; LONDOÑO,1996; QUATTROCCHI, 2006; FARRELLY, 1984).

Especificamente quanto a $M$. skvortzovii, há registro de sua ocorrência em São Paulo, Paraná e Rio Grande do Sul (SENDULSKY, 1995). No Estado do Paraná, representantes desta espécie foram coletados em localidades nos municípios de Palmas e General Carneiro, em região de Floresta Ombrófila Mista.

De acordo com legislação do Estado de São Paulo esta espécie está incluída na lista de espécies da flora ameaçadas de extinção (SMA, 2004).

\subsection{FENOLOGIA}

No que se refere à fenologia de M. skvortzovii, coleções conhecidas são de 1941, 1972-1974, sugerindo um ciclo de florescimento de 31-33 anos (SENDULSKY, 1995). Em 2004, registrou-se início de massivo florescimento e conseqüente mortalidade (2005-2007) de touceiras de $M$. skvortzovii em diversas localidades do sul do Estado do Paraná e norte de Santa Catarina. Com base nos registros anteriores de florescimento para esta região (Hatschbach et al. 28267, NY, SP, 1971), o florescimento e mortalidade registrados em 20042007 confirmam o ciclo fenológico de aproximadamente 33 anos.

\subsection{USOS E APLICAÇÕES}

Especificamente para M. skvortzovii, não se detectou registro de uso. Ressalta-se, no entanto, que dado ao potencial de identificação equivocada, especialmente, em relação à M. multiramea, esta ausência de registro pode não representar a realidade de uso desta espécie.

Dentre as espécies de bambus lenhosos nativos, presentes no Brasil, o gênero Merostachys, recebe destaque por ser um grupo com grande potencialidade de uso como produto florestal não madeirável (PFNM) (LONDOÑO, 1996).

De acordo com Farrelly (1984), de maneira geral o gênero Merostachys sp. é utilizado na confecção de instrumentos musicais, como flautas, e na confecção de cestos. No Brasil, segundo Bystriakova; Kapos; Lysenko (2004), o gênero Merostachys sp. é utilizado na fabricação de cestarias, no artesanato e, em menor, escala na construção.

No Brasil, dos 17 gêneros nativos de bambu, somente cinco, dentro os quais Merostachys, podem ser potencialmente utilizados na indústria de papel e celulose (KAHLER, 2006). Especificamente, cita-se para o cerrado brasileiro a obtenção de polpa celulósica a partir de espécies de Merostachys, juntamente com espécies nativas de Chusquea e Arundinaria (CEBRAC, 1999).

Guilherme; Ressel (2001) citam a taquara da espécie Merostachys riedeliana Rupr. como sendo bastante utilizada na construção de forros e balaios em propriedades rurais.

Em Santa Catarina, no Parque Estadual da Serra do Tabuleiro, outra espécie de taquara é utilizada pelos índios na confecção de cestaria - seu artesanato de maior visibilidade, importância e aceitação. Os guaranis Mbya, que habitam essa região, fabricam seus cestos, chamados de ajaka ou balaio, com três tipos de bambu, dentre eles Merostachys clausenii, também chamado de bambu pequeno ou takuapi (LITAIFF; DARELLA, 2000). 
Em Honduras, dentre os bambus utilizados para artesanato, inclui-se Merostachys argyronema Lindman que representa $66,6 \%$ da demanda de matéria prima (VALLE; BARBOSA; SOTO, 2000).

\section{CONCLUSÃO}

A partir da revisão bibliográfica do gênero Merostachys e da espécie $M$. skvortzovii pode-se concluir que as informações sobre aspectos biológicos, ecológicos sobre ambos são escassas. Desta forma, sugere-se a realização de estudos sobre estes aspectos, bem como a realização de levantamento etnobotânico da taquara em comunidades tradicionais próximas às áreas de ocorrência natural desta espécie como forma de iniciar e/ou estimular seu uso, desde que suportado pelo manejo sustentável das populações.

\section{REFERÊNCIAS}

BYSTRIAKOVA N.; KAPOS V.; LYSENKO I. Bamboo biodiversity: Africa, Madagascar and the Americas. Cambridge: UNEP-WCMC/INBAR, 2004. Disponível em: < http://www.unepwcmc.org/resources/publications/UNEP_WCMC_

_series/19.htm >. Acesso em: 22/04/2006.

CEBRAC Oportunidades de geração de renda no cerrado: texto para discussão. Brasília: CEBRAC, 1999.

CLAYTON, W. D.; HARMAN, K. T.; WILLIAMSON, H. Merostachys skvortzovii World Grass Species: descriptions, identification, and information retrieval, 2002. Disponível em: <http:/ /www.kew.org/data/grasses-db.html>. Acesso em: 08/11/2007

CROUZET,Y.; CROUZET, J.; STAROSTA, P. Bambus. Itália: Evergreen, 1998.

FARRELLY, D. The book of bamboo. San Francisco: Sierra Club Books, 1984.

GUILHERME, F. A. G.; RESSEL, K. Biologia floral e sistema de reprodução de Merostachys riedeliana (Poaceae: Bambusoideae). Revista Brasileira de Botânica, v. 24, n. 2, p. 205-211, 2001.

IBAMA Tecnologia do Bambu. Disponível em: <http://www.ibama.gov.br/ambtec>. Acesso 20/01/2008.

KAHLER, C. G. Global forest resources assessment 2005: report on bamboo thematic study in the framework of FAO FRA 2005 for Latin America (Brazil, Chile, Ecuador, Mexico, Peru). Working Paper, Rome, n. 123, 2006.

LITAIFF, A.; DARELLA, M. D. P. Os índios guarani Mbya e o Parque Estadual da Serra do Tabuleiro. XXII Reunião Brasileira de Antropologia. Fórum de Pesquisa 3: "Conflitos Sócioambientais e Unidades de Conservação." Brasília, 2000.

LONDOÑO, X. Diversity and distribution of new world bamboos, with special emphasis on the Bambuseae. INBAR Working Paper, New Dheli, n. 8, 1996. 
LOPEZ, O. H. Bambu su cultivo y aplicaciones en: fabricación de papel, construcción, arquitectura, ingeniería, artesanía. Colombia: Italgraf, 1974.

PANT, M. M.; VARMALI, J.C. Production and utilization of bamboos. Indian Forester, Dehra Dun, v. 107, n. 8, p. 465-476, 1981.

QUATTROCCHI, U. CRC world dictionary of grasses: common names, scientific names, eponyms, synonyms and etymology. Boca Raton: CRC Press, 2006.

SANQUETTA, C. R. Impacto do controle mecânico de taquaras (Bambusoideae) sobre a regeneração de araucária e espécies associadas numa área de Floresta Ombrófila Mista. General Carneiro: Labiratório de Inventário Florestal - UFPR, 2002. 250 p. (CNPq - Pesquisas Ecológicas PELD SITE 9: Floresta de Araucária e suas transições. Edital 001/97) Projeto em andamento

SENDULSKY, T. Merostachys multiramea (Poaceae: Bambusoideae: Bambuseae) and similar species from Brazil. Novon, Saint Louis, v. 5, p. 76-96, 1995.

SMA Espécies da flora ameaçadas de extinção no estado de São Paulo. Secretaria de Estado de Meio Ambiente: Resolução SMA 48, 2004. Disponível em: <http://sigam.ambiente.sp.gov.br/ Sigam2>. Acesso em: 25/03/2008.

SOUZA, V. C.; LORENZI, H. Botânica sistemática: guia ilustrado para identificação das famílias de Angiospermas da flora brasileira baseado em APG II. Nova Odessa: Instituto Plantarum, 2005, p. 177.

STAPLETON, C.M.A. Bamboos, Gramineae. In: JACKSON, J. K. Manual of Afforestation in Nepal. Kathmandu, 1987, p. 199-214. Disponível em: $<$ http://bambooidentification.co.uk/Jacksonbamboo.pdf>. Acesso em: 13/04/2006

TYRRELL, C. D.; SANTOS-GONÇALVES, A. P.; TRIPLETT, J.K.; CLARK, L. G. Polyphyly of the New World fan-branching bamboos (Poaceae: Bambusoideae). Botany \& Plant Biology Joint Congress. Resumo... Systematics Seccion, 2007. Disponível em: < http:// www.2007.botanyconference.org>. Acesso em: 15/03/2008.

VALLE, G. R. R.; BARBOSA, K. O.; SOTO, R. V. Evaluación de los productos forestales no madereros en América Central. FAO, Turrialba, 2000. 